\title{
Recycling of lignocellulosic waste materials to produce high-value products: single cell oil and xylitol
}

\author{
M. Enshaeieh • A. Abdoli • M. Madani • \\ M. Bayat
}

Received: 14 May 2014/Revised: 19 August 2014/ Accepted: 11 October 2014/Published online: 5 November 2014

(C) Islamic Azad University (IAU) 2015

\begin{abstract}
Application of microorganisms with ability of using environmental wastes such as lignocellulosic materials for converting them to high-value products is important from economical point of view. Valuable products such as single cell oil (SCO) have a high potential to be used in various industrial fields including biodiesel production. Other important products are polyalcohols like xylitol, which are applicable in the food and pharmaceutical industries. In this study, Rhodotorula yeast was isolated from the leaves of Benjamin. Afterward, SCO production was evaluated in a nitrogen-limited medium, and the obtained oil was analyzed by gas chromatography-mass spectrometery. Moreover, xylitol was produced in a media containing xylose and analyzed by high-performance liquid chromatography technique. The yeast strain was identified using polymerase chain reaction method. SCO and xylitol production was also evaluated in a medium containing lignocellulosic materials and other forestry residues. This strain produced SCO and dry biomass of 9.7 and $16.14 \mathrm{~g} / \mathrm{L}$, respectively. In addition, in a medium with $140 \mathrm{~g} / \mathrm{L}$ of xylose, xylitol production was found to be $49.28 \mathrm{~g} / \mathrm{L}$. Among waste materials, lipid content of $49 \%$ on grass hydrolysate was found to be incredible. The
\end{abstract}

M. Enshaeieh $(\bowtie) \cdot$ A. Abdoli

Young Researchers and Elite Club, Falavarjan Branch, Islamic

Azad University, Isfahan, Iran

e-mail: m_enshaeieh@yahoo.com

M. Madani

Assistant Professor of Medical Mycology, Department of Microbiology, Falavarjan Branch, Islamic Azad University, Isfahan, Iran

M. Bayat

Department of Pathobiology, Faculty of Veterinary Specialized

Sciences, Islamic Azad University, Science and Research

Branch, Tehran, Iran obtained strain was identified as Rhodotorula mucilaginosa. The results of this study show that by the isolation of yeast with the potential of making use of waste materials, highvalue products can be obtained. Therefore, it can be concluded that the mentioned bioprocess has not only environmental benefits but also is very important from economical view.

Keywords Rhodotorula mucilaginosa . Environmental wastes · Grass hydrolysate $\cdot$ Forestry residues

\section{Introduction}

Microbial lipid is similar to the oil obtained from plants and animals in terms of type and composition being composed of unsaturated fatty acids (Ratledge 2005; Meng et al. 2009; Liu et al. 2010; Papanikolaou and Aggelis 2003a). Accumulation of lipids in oleaginous microorganisms occurs with starvation of nitrogen or other nutrients instead of carbon (Fakas et al. 2008; Raschke and Knorr 2009; Papanikolaou et al. 2008; Vijayakumar et al. 2010). In addition to nitrogen limitation, phosphate limitation can improve lipid accumulation in oleaginous microorganisms (Muniraj et al. 2013). There are microorganisms that have an ability to produce and accumulate high levels of lipids in their cells, among which yeasts and fungi have received significant attention (Ratledge 2002; Khot et al. 2012; Katre et al. 2012). Oleaginous microorganisms can accumulate lipid more than $20 \%$ of their biomass, especially in the form of triacylglycerol (Susan and Maugeri 2014). Lipid production in the oleaginous microorganisms occurs in a two-stage process: In the first stage, cell growth occurs. This step goes to the end by eliminating some nutrition such as nitrogen. During the 
second stage, the excess amount of carbon accumulates in the form of intracellular lipid particles (Amaretti et al. 2010). Due to the similarity between microbial oil and vegetable oil, it is potential to be applied in biodiesel production (Karatay and Donmez 2010; Economou et al. 2010; El-Fadaly et al. 2009). In addition, it is possible to use these yeasts for converting lignocellulosic materials into high-value products. Also, improving production of single cell oil can potentially allow a novel production of biodiesel (Pirozzi et al. 2014; Santamauro et al. 2014). This makes them much more important from economical view because they can produce valuable products in addition to decreasing air pollution. Furthermore, single cell oil (SCO) can be used in various industrial applications such as cosmetic, pharmaceutical and nutritional sectors (Schulze et al. 2014). Microbial-based bioconversions can be used to obtain a variety of high-value products (Abghari and Chen 2014). Some kind of yeasts can metabolize pentoses, which shows the ability of them to use lignocellulosic agricultural residues and other low-cost materials. The economic value of this process becomes even more favorable when zero or negative waste materials are utilized as carbon source. By this bioprocess, the lack of energy source and also air pollution caused by fossil fuels can be solved. Various lowcost materials were utilized for microbial oil production. Of these materials, lignocellulosic substrate, that is the most abundant and renewable source in nature, could be a novel and ideal raw substrate for SCO production (Huang et al. 2013). Renewable energy sources, such as biodiesel, which are fatty acid methyl esters, have a lot of environmental advantages as they are biodegradable and nontoxic. The only problem of using this renewable energy sources is the high cost of biodiesel. Using microbial oil and cheap raw materials for its production can solve this problem (Zheng et al. 2012; Benjamas and Louhasakul 2013; Gong et al. 2013).

Sugar alcohols are a branch of polyalcohols that have advantages such as low calorie, antioxidant properties, sweetening and lowering of blood sugar. Therefore, they are used in food industry as additives and sugar substitutes (Granstrom et al. 2007). Xylitol is one of the polyalcohols, which is used widely. This sugar, with a high sweetening effect, has the same sweetness of sucrose but fewer calories, so its application in food industry such as chocolate, sweets and drinks would be appropriate (Altamirano et al. 2000; EL-Batal and Khalaf 2004). Xylitol can be produced by chemical reduction of xylose. This process needs to be rendered under the expensive condition of high pressure and temperature through aeration and purification steps. On the contrary, xylitol production using biotechnology and microorganisms has a great importance because of not requiring toxic catalyst and being environmentally safe (Cheng et al. 2010). Yeasts are very important for microbial conversion of xylose to xylitol and are acceptable microbial sources to be applied in various industries (Rao et al. 2007; Vakhlu and Kour 2006). Xylitol production is the result of intracellular accumulation of NADH under oxygen limitation. NADH inhibits xylitol dehydrogenase enzyme resulting in xylitol production in the yeasts (Granstrom 2002). Hemicellulose is main component of lignocellulosic materials; also, it is the second polysaccharide in the nature and a good source for xylose. The most abundant sugar monomers in hemicellulose are xylose compounds (Rao et al. 2008; Saxena et al. 2009). Thereby, identification of yeast with the ability of assimilating xylose and converting it to desired product would be valuable. Rhodotorula has the ability of growing on this carbon source and is capable of producing SCO in a nitrogen-limited medium. Some kind of bacteria can utilize lignocellulosic substrates and accumulate polyhydroxyalkanoates, but yeasts can accumulate lipid in the form of triacylglycerol (Sandhya et al. 2013).

The goal of this study was to isolate and identify yeast with the high potential of producing valuable products for industrial applications. The isolated yeast was not only able to produce high amounts of SCO in appropriate condition but also it could produce high levels of xylitol. The potential of converting lignocellulosic compounds to valuable products by this strain was also investigated in this study. This study was done in 2013-2014 at Young Researchers and Elite Club of Flavarjan Islamic Azad University.

\section{Materials and methods}

Isolation and selection of oleaginous yeasts

To isolate the yeasts, samples such as leaves (including leaves of Benjamin), flowers (including sunflower) and fruits (including almond, sesame, corn and olive) were soaked in water at $25^{\circ} \mathrm{C}$ for 3 days. Then, $0.1 \mathrm{~mL}$ of the above solution was transferred to $250-\mathrm{mL}$ flask containing $50 \mathrm{~mL}$ enrichment medium composed of $100 \mathrm{~g} / \mathrm{L}$ glycerol, $1 \mathrm{~g} / \mathrm{L}\left(\mathrm{NH}_{4}\right)_{2} \mathrm{SO}_{4}, 1 \mathrm{~g} / \mathrm{L} \mathrm{KH}_{2} \mathrm{PO}_{4}, 1 \mathrm{~g} / \mathrm{L} \mathrm{MgSO}_{4} \cdot 7 \mathrm{H}_{2} \mathrm{O}$ and $1 \mathrm{~g} / \mathrm{L}$ yeast extract. The obtained pre-cultured yeast was placed in a shaker at $180 \mathrm{rpm}$ and $30{ }^{\circ} \mathrm{C}$ for $96 \mathrm{~h}$.

Afterward, $0.1 \mathrm{~mL}$ of the pre-cultured yeasts were added to the solid medium containing $20 \mathrm{~g} / \mathrm{L}$ glucose, $2 \mathrm{~g} /$

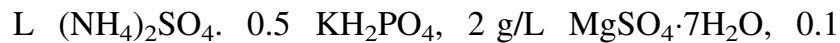
$\mathrm{CaCL}_{2}$ and $2 \%$ agar and kept for $48 \mathrm{~h}$ at $28{ }^{\circ} \mathrm{C}$. The obtained colonies on the plate were purified according to their different morphologies. To obtain pure colonies, this process was carried out for several times. Then, the purified colonies were kept on YPD (yeast extract peptone dextrose agar) slants, and the new slants were prepared in every 
1-2 months. Finally, the isolates were evaluated by Sudan black B staining (Pan et al. 2009).

Lipid production in isolated yeasts

Oleaginous yeasts were cultured in a nitrogen-limited medium for 4 days. This medium included glucose $(40 \mathrm{~g} /$ L), $\left(\mathrm{NH}_{4}\right)_{2} \mathrm{SO}_{4}(2 \mathrm{~g} / \mathrm{L}), \mathrm{KH}_{2} \mathrm{PO}_{4}(7 \mathrm{~g} / \mathrm{L}), \mathrm{NaH}_{2} \mathrm{PO}_{4}(2 \mathrm{~g} /$ $\mathrm{L}), \mathrm{MgSO}_{4} \cdot 7 \mathrm{H}_{2} \mathrm{O}(1.5 \mathrm{~g} / \mathrm{L})$ and yeast extract $(1 \mathrm{~g} / \mathrm{L})$. Fifty milliliters of this medium was poured into a $250-\mathrm{mL}$ Erlenmeyer flask and placed on a shaker at $180 \mathrm{rpm}$ and $28{ }^{\circ} \mathrm{C}$. Before culturing in nitrogen-limited medium, the yeasts were activated in inoculation medium containing glucose $(15 \mathrm{~g} / \mathrm{L}),\left(\mathrm{NH}_{4}\right)_{2} \mathrm{SO}_{4}(5 \mathrm{~g} / \mathrm{L}), \mathrm{KH}_{2} \mathrm{PO}_{4}(1 \mathrm{~g} / \mathrm{L})$, $\mathrm{MgSO}_{4} \cdot 7 \mathrm{H}_{2} \mathrm{O}(0.5 \mathrm{~g} / \mathrm{L})$ and yeast extract $(0.5 \mathrm{~g} / \mathrm{L})$ grown at $28{ }^{\circ} \mathrm{C}$ at $180 \mathrm{rpm}$ for $48 \mathrm{~h}$ (Pan et al. 2009; Kraisintu et al. 2010).

Lipid extraction was performed, based on Bligh and Dyer method with few modifications (Pan et al. 2009). Fifty milliliters of the sample was centrifuged at $6,000 \mathrm{rpm}$ for $8 \mathrm{~min}$. Afterward, the yeasts were washed with $50 \mathrm{~mL}$ of distilled water. Then, $10 \mathrm{~mL}$ of $\mathrm{HCl}(4 \mathrm{M})$ was added and incubated at $70{ }^{\circ} \mathrm{C}$ for $2 \mathrm{~h}$, and acid hydrolyzed mass was also stirred with $20 \mathrm{~mL}$ chloroform/methanol mixture (1:1) at room temperature for $2-3 \mathrm{~h}$. At the end, centrifugation was done at $6,000 \mathrm{rpm}$ for $3 \mathrm{~min}$ at room temperature to separate the aqueous upper phase and organic lower phases. The lower phase containing lipid was recovered with Pasteur pipette and evaporated in a vacuum. Afterward, dry lipid was weighed (Pan et al. 2009). Lipid content in each trial condition was determined by the following equation:

SCO productivity (lipid content)

$=$ SCO Weight $(\mathrm{g} / \mathrm{L}) /$ Cell dry weight $(\mathrm{g} / \mathrm{L}) \times 100$

(Kraisintu et al. 2010).

Portions of $5 \mathrm{~mL}$ cultures were harvested by centrifugation at $8,000 \mathrm{rpm}$ for $10 \mathrm{~min}$. Harvested biomass was washed twice with $5 \mathrm{~mL}$ of distilled water and then dried at $70{ }^{\circ} \mathrm{C}$ to obtain constant mass. The biomass was determined gravimetrically (Sriwongchai et al. 2013; Altamirano et al. 2000).

Analysis of SCO production by gas chromatographymass spectrometry (GC-MS)

Analysis by FTIR spectroscopy and GC-MS can show that the obtained oil has a similar structure to the plants oil and can be converted to the biodiesel or used for other industrial purposes. The obtained oil was used for transesterification using methanol with molar ratio of $30: 1$, at $55^{\circ} \mathrm{C}$ and at $180 \mathrm{rpm}$ for $5.5 \mathrm{~h}$ as a reaction time. Based on oil weight, $80 \%$ sulfuric acid was used as a catalyst (Liu et al. 2004; Wu and Miao 2006). Afterward, the upper layer containing biodiesel was separated by petroleum ether. Fatty acid methyl esters were analyzed by GC-MS (HP5890, serieII gas chromatography, HP 5972 mass selective detector) (Enshaeieh et al. 2012).

Lipid production using lignocellulosic materials as sole carbon sources

Before using lignocellulosic materials such as wheat straw, rice bran, grass and leaves, they must be prepared by acid hydrolysis. For this purpose, the materials were ground and then hydrolyzed by using sulfuric acid $(5 \%)$. This digestion was performed at a solid/liquid ratio of $1: 8$, and upon completion of the process, it was autoclaved at $110{ }^{\circ} \mathrm{C}$ for $25 \mathrm{~min}$. Afterward, the suspension was centrifuged to remove unhydrolyzed residues (Dai et al. 2007). Ten milliliter of this suspension was brought to $45 \mathrm{~mL}$ with sterile water. After adjusting the $\mathrm{pH}$ at 6 , other components (the same as nitrogen-limited medium) were added. Five milliliter of the inoculation was added and incubated at optimum condition.

Effects of nutrient composition, $\mathrm{pH}, \mathrm{rpm}$, incubation time and temperature on lipid production

Effects of nutrient composition, such as glucose and ammonium sulfate concentration, and physical parameters, such as $\mathrm{pH}, \mathrm{rpm}$, temperature and time of incubation, on lipid production were evaluated. Glucose concentration varied at 50,70, 90, 110, and $130 \mathrm{~g} / \mathrm{L}$. Effects of combined organic nitrogen sources (yeast extract and peptone at $1 \mathrm{~g} /$ L) and inorganic compounds (ammonium sulfate and ammonium chloride at $1 \mathrm{~g} / \mathrm{L}$ ) on lipid production were investigated. Moreover, lipid production was evaluated under different ammonium sulfate concentrations of $0.5,1$, 1.5 and $2 \mathrm{~g} / \mathrm{L}$. Other factors were variables including: $\mathrm{pH}$ rates of 4, 5, 6, 7 and 8 ; temperatures of 20,25 and $30{ }^{\circ} \mathrm{C}$; and incubation times of 24, 48, 72 and $96 \mathrm{~h}$ (Kraisintu et al. 2010;. Enshaeieh et al. 2013a, b; Enshaeieh et al. 2014).

Production of xylitol by isolated yeast

A loop of activated yeast was transferred to $50-\mathrm{mL}$ flask of a pre-production xylitol medium containing $(\mathrm{g} / \mathrm{L})$ : xylose 40 , ammonium sulfate 5 , potassium dihydrogen phosphate 2 , magnesium sulfate 0.5 , peptone 1 and yeast extract 5 with the $\mathrm{pH}$ rate of 5.5 , incubated at $30{ }^{\circ} \mathrm{C}$ with $180 \mathrm{rpm}$ for $48 \mathrm{~h}$. Then, inoculation was transferred $(5 \%)$ into xylitol production medium (the same as pre-production culture), and xylitol production was assessed every $24 \mathrm{~h}$ for 5 days (Cheng et al. 2010). 
Initial xylose concentration for xylitol production by yeast isolates was optimized. Xylose concentration of 80-160 g/L was investigated, and based on the production efficiency, the best concentration of xylose for xylitol production by this strain was selected. Xylitol production on grass hydrolysate was also investigated.

Evaluation of xylitol production using thin layer chromatography (TLC) and high-performance liquid chromatography (HPLC) techniques

At first, xylitol production by the yeast strain was evaluated qualitatively by TLC as a simple and rapid analytical method. This method is based on segregating compounds with polarity and molecular weight differences. Thus, the amount of $1 \mu \mathrm{l}$ of medium containing xylitol was placed on TLC silica paper $\left(60 \mathrm{~F}_{254}\right)$, and the paper was put in solvent containing propanol-butanol-water with a ratio of $7: 2: 1$. In order to make the appearance of blemishes, the paper was sprayed (by sodium hydroxide-potassium permanganate), and after drying, xylitol production was examined (Zagustina et al. 2001).

The amount of xylitol production by the yeast strain was measured using HPLC. Also, the remaining amount of xylose obtained by fermentation process was calculated using this method. In this method, Nucleosil 100-5 NH2 amine column (manufactured by Knauer, Germany) was used. Mobile phase was acetonitrile/water (80:20) that passed through the column with the rate of $1 \mathrm{~mL} / \mathrm{min}$. Refractive index (RI) detector was used, and 20 microliters of sample was injected into the device. To measure the unknown samples, standard samples were injected into the system. Then, the surfaces under the curve were calculated, and the standard curve was prepared.

Identification of the yeast by sequencing ribosomal RNA

The isolated yeast was identified by sequencing a fragment of genome. Primers used in this study were internal transcribed spacer (ITS). The polymerase chain reaction (PCR) was done using primers ITS1 (5'TCCGTAGGTGAACCTG $\mathrm{CGG}^{\prime}$ ) as a forward primer and ITS4 (5'TCCTCCGCT TATTGATATGC3') as a reverse primer (Deak et al. 2000). Purity and relative size of the PCR products were obtained on agarose gel $(1.5 \%)$, and then, the sequence was determined and searched in NCBI Site to identify the genus and species of yeast. PCR included three stages: the initial denaturation (at $95^{\circ} \mathrm{C}$ for $5 \mathrm{~min}$ ), 30 cycles (at $95{ }^{\circ} \mathrm{C}$ for $30 \mathrm{~s}$, at $55^{\circ} \mathrm{C}$ for $30 \mathrm{~s}$ and at $72{ }^{\circ} \mathrm{C}$ for $1 \mathrm{~min}$ ) and the final extension (at $72^{\circ} \mathrm{C}$ for $10 \mathrm{~min}$ ).

\section{Results and discussion}

Ten out of the 70 isolated yeasts were oleaginous. The oleaginous yeasts, stained by Sudan black B, had black lipid granules which were observed under optical microscope. These strains were selected for lipid extraction. The result of lipid extraction has been indicated in Table 1 . The $\mathrm{F}$ colonies were used for further investigations and identified by PCR method.

Identifying the yeast by sequencing ribosomal RNA

Fragments obtained from the yeast after PCR were used on agarose gel electrophoresis to determine the relative size and purity of them. The length of obtained fragments was different from that of primers ITS1 and ITS2 in various yeasts including "a part of ITS2-5.8srRNA- ITS118srRNA and a part of 28srRNA." Figure 1 shows the agarose gel electrophoresis of PCR products of yeast isolated in this study. Rhodotorula mucilaginosa was identified after sequencing and matching the specified isolation on NCBI site.

\section{Lipid analysis by GC-MS}

The result of GC-MS shows the potential of microbial oil for industrial applications. Composition of fatty acid methyl esters was as follows: myristic acid (C14:0) $1.98 \%$, palmitic acid $16.62 \%$ (C16:0), stearic acid (C18:0) $1.63 \%$, oleic acid (C18:1) 69.45\%, linoleic acid (C18:2) $5.78 \%$, $\alpha$-linolenic acid (C18:3) $0.3 \%$ and very low concentration of other fatty acid methyl esters (trace fatty acids $4.24 \%$ ). Microbial oil is a good feedstock for biodiesel production by being dominated by monounsaturated

Table 1 Lipid production $(\mathrm{g} / \mathrm{L})$, dry biomass $(\mathrm{g} / \mathrm{L})$ and lipid productivity $(\%)$ in isolated yeasts

\begin{tabular}{llcl}
\hline $\begin{array}{l}\text { Name of } \\
\text { colonies }\end{array}$ & $\begin{array}{l}\text { Lipid } \\
(\mathrm{g} / \mathrm{L})\end{array}$ & $\begin{array}{l}\text { Dry biomass } \\
(\mathrm{g} / \mathrm{L})\end{array}$ & $\begin{array}{l}\text { Lipid productivity } \\
(\%)\end{array}$ \\
\hline $\mathrm{A}$ & 1.93 & 8.72 & 22.13 \\
$\mathrm{~B}$ & 3.14 & 13.12 & 23.93 \\
$\mathrm{C}$ & 2.16 & 9.34 & 23.12 \\
$\mathrm{D}$ & 1.89 & 8.70 & 21.72 \\
$\mathrm{E}$ & 2.67 & 11.13 & 23.98 \\
$\mathrm{~F}$ & 6.17 & 17.82 & 34.62 \\
$\mathrm{G}$ & 1.94 & 8.16 & 23.77 \\
$\mathrm{H}$ & 0.81 & 3.89 & 20.82 \\
$\mathrm{I}$ & 1.71 & 7.53 & 22.70 \\
$\mathrm{~J}$ & 1.92 & 8.37 & 22.93 \\
\hline
\end{tabular}




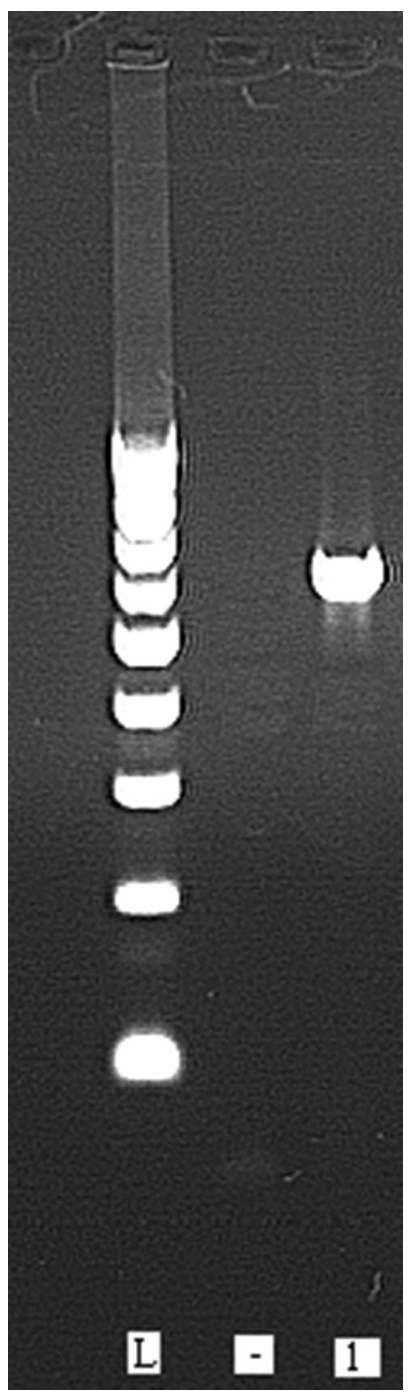

Fig. 1 Image of gel electrophoresis of PCR products of isolated strain. $L$ Ladder (Fermentas, 100 base), - negative control (distilled water), and 1 Rhodotorula mucilaginosa

C16 and C18 fatty acids (Amaretti et al. 2012; Tanimura et al. 2014). Mattanna et al. (2014) analyzed the fatty acid profile of sixteen oleaginous yeasts, and the highest fatty acid was oleic acid in all of the evaluated yeasts.

\section{Optimization of microbial lipid production}

Table 2 shows the results of optimization of various parameters influencing lipid production. At each trial, only one factor is variable and the others are constant as in one factorial method. The selected amount was used for the next step. During each production process, optimization would be necessary to raise the efficiency and reduce the cost. Optimization cause less time-consuming and also less cost is required, so it becomes valuable from economical point of view. It was shown that optimization of chemical parameters such as carbon and nitrogen sources, carbon concentration and ammonium concentration can effect on lipid production in oleaginous yeasts (Enshaeieh et al. 2013b). Also, the effect of different carbon sources such as glucose, xylose, glycerol and rice bran and different nitrogen sources such as yeast extract, peptone, urea, (NH4) ${ }_{2} \mathrm{SO}_{4}$ and $\mathrm{NH}_{4} \mathrm{Cl}$ was investigated on lipid production (Enshaeieh et al. 2012). In another research, the effect of physical parameters on lipid production by oleaginous yeasts was evaluated (Enshaeieh et al. 2013a); so medium composition and fermentation condition have much effect on lipid production.

\section{Lipid production using lignocellulosic materials}

The results of lipid production on xylose and lignocellulosic materials in optimized condition are presented in Table 3. The results obtained in this study were excellent and showed high potential for lipid production by the evaluated yeast strain. Dai et al. (2007) used rice and corn straw and the yeast Rhodotorula glutinis for lipid production and achieved the highest lipid content of $11.78 \%$. In this study, lipid production by $R$. mucilaginosa on xylose, grass and leaves hydrolysate was $8.1,7.5$ and $6.8 \mathrm{~g} / \mathrm{L}$, respectively. Lipid productivity (lipid content) of this strain on these substrates was 51.33, 49.02 and $45.12 \%$, respectively. Pan et al. (2009) isolated yeast strains capable of assimilating xylose and lipid production. Among the 13 strains isolated by them, the highest amount of lipid production was $5.68 \mathrm{~g} / \mathrm{L}(23.3 \%)$ in a medium containing $40 \mathrm{~g} / \mathrm{L}$ xylose.

\section{Evaluation of xylitol production using TLC technique}

This strain is capable of producing xylitol from xylose after $24 \mathrm{~h}$. Produced xylitol in the third day was evaluated by TLC, and the result is shown in Fig. 2 (10 g/L xylitol was used as control).

\section{Analysis of xylitol production by HPLC}

HPLC method was used in order to measure and validate the amount of xylitol production. The amount of residual xylose in fermentation process was calculated using this method. The biomass can also be seen in Fig. 3. Using HPLC method, the maximum xylitol production by the strain was determined to be $25.32 \mathrm{~g} / \mathrm{L}$ on the third day. The results show that the measured value in colorimetric assay was consistent with HPLC method.

Optimum concentration of xylose for xylitol production

Carbon source was optimized in order to increase the xylitol production in $R$. mucilaginosa. The results showed 
Table 2 Lipid production, dry biomass and lipid production of Rhodotorula mucilaginosa

\begin{tabular}{|c|c|c|c|}
\hline Conditions & $\begin{array}{l}\text { Lipid } \\
\text { production } \\
(\mathrm{g} / \mathrm{L})\end{array}$ & $\begin{array}{l}\text { Dry } \\
\text { biomass } \\
(\mathrm{g} / \mathrm{L})\end{array}$ & $\begin{array}{l}\text { Lipid } \\
\text { production } \\
(\%)\end{array}$ \\
\hline \multicolumn{4}{|c|}{ Glucose concentration $(g / L)$} \\
\hline 50 & 4.35 & 13.55 & 32.1 \\
\hline 70 & 5.46 & 14.18 & 38.5 \\
\hline 90 & 6.58 & 14.78 & 44.52 \\
\hline 110 & 5.87 & 14.67 & 40.01 \\
\hline 130 & 5.12 & 13.58 & 37.7 \\
\hline \multicolumn{4}{|l|}{ Nitrogen source $(g / L)$} \\
\hline $\begin{array}{l}\text { Yeast extract and } \\
\text { ammonium sulfate (1) }\end{array}$ & 6.97 & 14.86 & 46.9 \\
\hline $\begin{array}{l}\text { Yeast extract and } \\
\text { ammonium chloride } \\
\text { (1) }\end{array}$ & 6.45 & 14.33 & 45.01 \\
\hline $\begin{array}{l}\text { Peptone and ammonium } \\
\text { sulfate (1) }\end{array}$ & 5.9 & 13.65 & 43.22 \\
\hline $\begin{array}{l}\text { Peptone and ammonium } \\
\text { chloride (1) }\end{array}$ & 5.25 & 12.65 & 41.5 \\
\hline \multicolumn{4}{|c|}{ Ammonium sulfate concentration $(\mathrm{g} / \mathrm{L})$} \\
\hline 0.5 & 5.68 & 13.08 & 43.42 \\
\hline 1 & 6.9 & 15.23 & 45.3 \\
\hline 1.5 & 5.45 & 13.29 & 41 \\
\hline 2 & 4.67 & 11.91 & 39.21 \\
\hline \multicolumn{4}{|l|}{$p H$} \\
\hline 4 & 6.2 & 13.27 & 46.72 \\
\hline 5 & 7.76 & 15.36 & 50.52 \\
\hline 6 & 7.5 & 15.3 & 49.02 \\
\hline 7 & 5.5 & 13.38 & 41.1 \\
\hline 8 & 4.1 & 10.43 & 39.31 \\
\hline \multicolumn{4}{|l|}{ Temperature $\left({ }^{\circ} \mathrm{C}\right)$} \\
\hline 20 & 7.8 & 15.2 & 51.31 \\
\hline 25 & 8.1 & 14.03 & 57.73 \\
\hline 30 & 6.9 & 14.08 & 49 \\
\hline \multicolumn{4}{|l|}{ Time of incubation (h) } \\
\hline 24 & 6.75 & 13.55 & 49.81 \\
\hline 48 & 7.89 & 14.88 & 53.02 \\
\hline 72 & 9.7 & 16.14 & 60.09 \\
\hline 96 & 8.85 & 15.18 & 58.3 \\
\hline
\end{tabular}

that increase of xylose concentration from 80 to $140 \mathrm{~g} / \mathrm{L}$ caused higher xylitol production in $R$. mucilaginosa, while further increase of xylose concentration reduced the xylitol production. Considering the production based on sugar consumed ( $\mathrm{Y}_{\mathrm{P} / \mathrm{S}}: 0.59 \mathrm{~g} / \mathrm{g}$ ) and cell mass $\left(\mathrm{Y}_{\mathrm{P} / \mathrm{X}}: 3 / 35 \mathrm{~g} / \mathrm{g}\right)$, the best concentration of xylose for xylitol production by R. mucilaginosa was obtained to be $140 \mathrm{~g} / \mathrm{L}$. The maximum amount of xylitol $(49 / 28 \mathrm{~g})$ was obtained at this concentration of sugar. It was also revealed that increasing
Table 3 Lipid production on agricultural residues as sole carbon sources

\begin{tabular}{llll}
\hline Condition & $\begin{array}{l}\text { Lipid } \\
\text { production } \\
\left(\mathrm{g} \mathrm{L}^{-1}\right)\end{array}$ & $\begin{array}{l}\text { Biomass } \\
\left(\mathrm{g} \mathrm{L}^{-1}\right)\end{array}$ & $\begin{array}{l}\text { Lipid } \\
\text { productivity (\%) }\end{array}$ \\
\hline Xylose & 8.1 & 15.78 & 51.33 \\
Wheat straw & 5.9 & 13.84 & 42.63 \\
Rice bran & 6.2 & 16.21 & 38.24 \\
Grass hydrolysate & 7.5 & 15.30 & 49.02 \\
Leaves hydrolysate & 6.8 & 15.07 & 45.12 \\
\hline
\end{tabular}

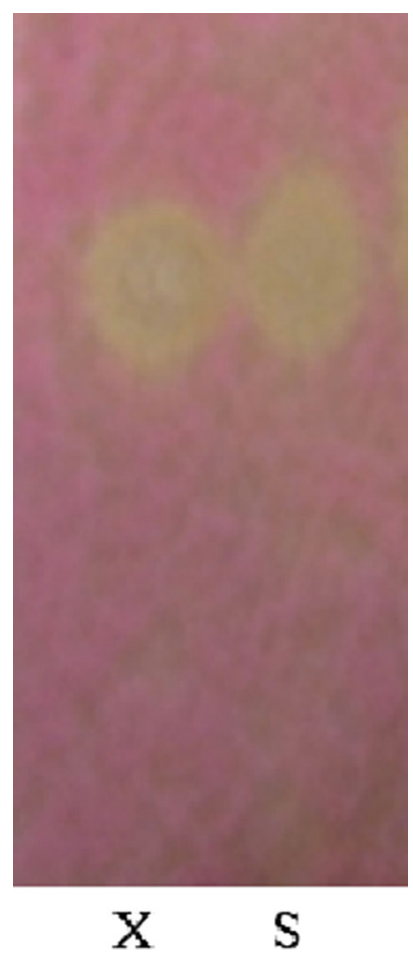

Fig. 2 TLC of xylitol production by Rhodotorula musillaginosa. Bond of xylitol produced by yeast (S) versus standard band (xylitol) (X)

of xylose concentration led to higher fermentation time (Table 4). Xylitol production on grass hydrolysate was $20.65 \mathrm{~g} / \mathrm{L}$ and showed the great potential of this yeast in assimilating and converting hydrolysate to valuable products. Ikeuchi et al. (1999) concluded that the effect of initial concentration of xylose increased from 50 to $300 \mathrm{~g} /$ $\mathrm{L}$ for optimization of xylitol production in Candida 599-9. In their study, the best sugar concentration was $200 \mathrm{~g} / \mathrm{L}$, in which $173 \mathrm{~g} / \mathrm{L}$ of xylitol was produced. Cheng et al. (2010) evaluated the effect of xylose concentration increase on xylitol production by strain Candida tropicalis W103 isolated from soil. They found out that the best xylose concentration was $120 \mathrm{~g} / \mathrm{L}$ with a yield of $0.73 \mathrm{~g} / \mathrm{g}$ and the xylitol of $87.1 \mathrm{~g} / \mathrm{L}$. As these studies show, the influence of 
Fig. 3 The produced xylitol and xylose consumed by Rhodotorula mucilaginosa and their measurements using HPLC (xylose in the medium was $4 \%$ )

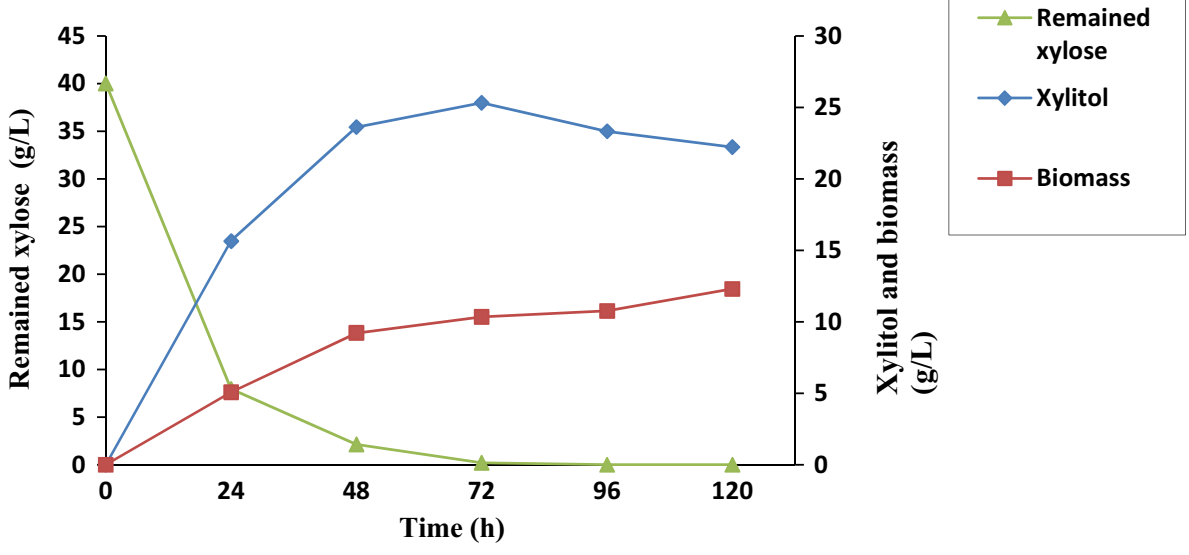

the initial xylose concentration on xylitol production depends on type of yeast strain as well as culture conditions (Mussatto and Roberto 2008).

Application of microbial lipid as an alternative source of oil and fat for human was considered in the early twentieth century. The oil stored in yeast can be used for three different purposes: (1) The oil being rich in essential unsaturated fatty acids has potential to be applied in dietary supplements. (2) Composition of the oil is similar to cocoa butter, and it can be used instead. (3) The oil is a renewable source, and can be used in biofuel production (Beopoulos et al. 2008). Effectiveness of each substrate for lipid accumulation is highly dependent on the type of microorganisms and fermentation conditions. Effective substrate for lipid accumulation in microorganisms can be detected by doing experiments (Fakas et al. 2008).

Rhodotorula mucilaginosa had a high potential for lipid synthesis. Lipid content and lipid production of this strain were $60.09 \%$ and $9.7 \mathrm{~g} / \mathrm{L}$ on glucose, respectively. (Leesing and Baojungharn 2011) isolated oleaginous strain Torulaspora globosa YU5/2 and reported lipid production of $4.16 \mathrm{~g} / \mathrm{L}$ in nitrogen-limited medium with $80 \mathrm{~g} / \mathrm{L}$ glucose as a carbon source. Most of investigations on lipid production focus on glucose, but the high cost of this substrate persuades much effort to find low-cost carbon sources such as lignocellulosic materials and also oleaginous yeasts that can utilize this substrate (Enshaeieh et al. 2012). SCO production from lignocellulosic materials containing xylose attracted a lot of attention, and yeast strains with the ability of using xylose in lignocellulosic hydrolysate have potential for industrial application. In lignocellulosic hydrolysate, there are some inhibitors such as furfural and formic acid that limited yeast growth and decrease lipid production comparing with lipid yield on xylose (Zhao et al. 2012). Table 5 shows a comparison on lipid production of different oleaginous yeasts on lignocellulosic substrates. Comparison of Tables 3 and 5 shows different potential of oleaginous yeasts in converting lignocellulosic mass to intracellular lipid.

The best lipid production in the yeast $R$. mucilaginosa was obtained on glucose as a carbon source. Fei et al. (2010) reported that many studies had been done on lipid production in the oleaginous microorganisms on glucose as a carbon source. Vijayakumar et al. (2010) evaluated the effect of different carbon sources such as glucose, fructose and sucrose on lipid production in Rhodotorula glutinis, Rhodosporidium toruloides and Lipomyces starkey. Among the various carbon sources, glucose produced higher biomass and lipid contents. Among the yeast strains evaluated by them, Rhodotorula glutinis exhibited a higher lipid production and biomass of 2.43 and $10.21 \mathrm{~g} / \mathrm{L}$ on glucose, respectively. Some microalgae can accumulate lipid by $\mathrm{CO}_{2}$ as carbon source which makes them good candidate for biodiesel production (Huang and Su 2014), but yeasts have high growth rate, can accumulate lipid in separate lipid bodies, can use low-cost fermentation media, also less

Table 4 Effect of xylose concentration increase on xylitol production by strain Rhodotorula mucilaginosa

\begin{tabular}{lllllll}
\hline Xylose concentration $(\mathrm{g} / \mathrm{L})$ & Time $(\mathrm{h})$ & Biomass $(\mathrm{g} / \mathrm{L})$ & Sugar consumed $(\mathrm{g} / \mathrm{L})$ & Xylitol $(\mathrm{g} / \mathrm{L})$ & $\mathrm{Y}_{\mathrm{P} / \mathrm{S}}(\mathrm{g} / \mathrm{g})$ & $\mathrm{Y}_{\mathrm{P} / \mathrm{X}}(\mathrm{g} / \mathrm{g})$ \\
\hline 80 & 192 & 12.8 & 74.29 & 34.28 & 0.46 & 2.67 \\
100 & 192 & 13.2 & 77.15 & 37.14 & 0.48 \\
120 & 192 & 13.7 & 80 & 44.28 & 0.55 & 2.81 \\
140 & 192 & 14.7 & 82.86 & 49.28 & 0.59 & 3.35 \\
160 & 192 & 12.2 & 57.16 & 31.42 & 0.54 \\
\hline
\end{tabular}

$\mathrm{Y}_{\mathrm{P} / \mathrm{S}}(\mathrm{g} / \mathrm{g})$ : ratio of xylitol produced $(\mathrm{g} / \mathrm{L})$ to the amount of sugar consumed $(\mathrm{g} / \mathrm{L}) . \mathrm{Y}_{\mathrm{P} / \mathrm{X}}(\mathrm{g} / \mathrm{g})$ : ratio of xylitol produced (g/L) to the amount of cell biomass (g/L) (Mussatto and Roberto 2008) 
Table 5 Comparison of lipid production between oleaginous yeasts on different lignocellulosic substrate

\begin{tabular}{cllc}
\hline Yeast strains & Carbon source & $\begin{array}{l}\text { Lipid } \\
\text { content } \\
(\%)\end{array}$ & References \\
\hline $\begin{array}{c}\text { Tricosporon } \\
\text { fermentens } \\
\begin{array}{c}\text { Rhodotorula } \\
\text { glutinis }\end{array}\end{array}$ & Rice straw & 40.1 & $\begin{array}{c}\text { Huang et al. } \\
(2009)\end{array}$ \\
$\begin{array}{c}\text { Cryptococcus } \\
\text { curvatus }\end{array}$ & Wheat straw & 33.5 & $\begin{array}{c}\text { Tao et al. } \\
(2010)\end{array}$ \\
$\begin{array}{c}\text { Yarrowia } \\
\text { lipolytica }\end{array}$ & $\begin{array}{c}\text { Sugar cane } \\
\text { hydrolysate }\end{array}$ & 58.5 & $\begin{array}{c}\text { Tsigie et al. } \\
(2011)\end{array}$ \\
$\begin{array}{c}\text { Mortierella } \\
\text { isabellina }\end{array}$ & $\begin{array}{c}\text { Rice hull } \\
\text { hydrolysat }\end{array}$ & 51.2 & $\begin{array}{c}\text { Economou } \\
\text { et al. (2011) }\end{array}$ \\
$\begin{array}{c}\text { Yarrowia } \\
\text { lipolytica }\end{array}$ & $\begin{array}{c}\text { Sugarcane bagasse } \\
\text { hydrolysates }\end{array}$ & 58.5 & $\begin{array}{c}\text { Tsigie et al. } \\
(2011)\end{array}$ \\
$\begin{array}{c}\text { Polg } \\
\text { Trichosporon } \\
\text { dermatis }\end{array}$ & $\begin{array}{c}\text { corncobs } \\
\text { hydrolysates }\end{array}$ & 40.1 & $\begin{array}{c}\text { Huang et al. } \\
(2012)\end{array}$ \\
\hline
\end{tabular}

labor is required and scaling up is easier. These advantages attracted lots of attentions to oleaginous yeasts ( $\mathrm{Li}$ et al. 2008).

The best concentration for carbon source in the yeast $R$. mucilaginosa was obtained at $90 \mathrm{~g} / \mathrm{L}$. Syed et al. (2006) reported that increase of glucose concentration resulted in decrease of dry biomass. This could be due to intolerance of yeast cells to high concentrations of glucose which could intrinsically increase the osmotic potential. (Leesing and Baojungharn 2011) reported the highest lipid production in glucose concentration of $80 \mathrm{~g} / \mathrm{L}$ and showed that further increase of glucose concentrations had an inhibitory effect on lipid production. The highest lipid production in $R$. mucilaginosa was obtained at $\mathrm{pH} 5$, temperature of $25{ }^{\circ} \mathrm{C}$ and in $72 \mathrm{~h}$. Some oleaginous yeast such as Yarrowia lipolytica can use their lipid storage after $72 \mathrm{~h}$, however, carbon source in still in the medium (Papanikolaou et al. 2001). This microorganism showed the tendency to degrade its storage lipids, although high carbon source remained unconsummated in the culture medium, and this phenomenon is called lipid turnover (Papanikolaou and Aggelis 2003, 2011). Lipid production in the evaluated yeast in this study starts to decrease after $72 \mathrm{~h}$ which maybe has the same reason. Zhu et al. (2008), Easterling et al. (2009), Li et al. (2005) reported that lipid production capability was affected by the $\mathrm{pH}$ of medium, and the best $\mathrm{pH}$ for yeast cells is between 5 and 6. Dai et al. (2007) optimized the cultivation condition for the yeast Rhodotorula glutinis and reached the highest content of $49.25 \%$ at $28{ }^{\circ} \mathrm{C}$ and $\mathrm{pH}$ of 5 on glucose as a carbon source.

Considering the disadvantages of chemical method, microbial production of xylitol would be a good alternative. Xylitol is usually produced by the microorganisms that consumed xylose. The most important factor affecting the production of xylitol is the initial xylose concentration. Bura et al. (2012) reported that yeast strain $R$. mucilaginosa PTD3 was isolated from poplar stems capable of producing xylitol with a yield of $67 \%$ from $150 \mathrm{~g} / \mathrm{L}$ xylose. In this study, the effect of different xylose concentrations on xylitol production by $R$. mucilaginosa was investigated, and the results showed that increase of xylose concentrations could stimulate the increase of xylitol production and lead to longer fermentation time. By this strain, the best concentration of xylose for xylitol production was found to be $140 \mathrm{~g} / \mathrm{L}$, and xylitol production at this concentration was $49.28 \mathrm{~g} / \mathrm{L}$. Moreover, higher increases led to the reduction in xylitol production which was due to the osmotic pressure of xylose concentrations. In most of the studies, the carbon source xylose has been used as a substrate for xylitol production. Xylose is also an abundant sugar in hemicellulosic hydrolysate. Xylitol production from lactose using whey was done by a threestep process as well (Toyoda and Ohtaguchi 2009).

\section{Conclusion}

The prominent aspect of this study is the isolation of the yeast strain with potential to be applied in different industrial cases. The yeast strain isolated in this study has the potential to produce SCO in a nitrogen-limited medium and to produce xylitol in a medium containing xylose. Both SCO and xylitol being extremely valuable materials can be applied in various fields. This strain bears the potential of using hydrolysis of lignocellulosic materials which rely on xylose as a main component. This ability is very important from an environmental point of view. Optimization of physical and chemical parameters can lead to higher production and, by changing the medium condition, can convert the yeast to a desired product. Isolation of such yeast with a high potential for production of important bio-products can be very valuable from an economical point of view.

Acknowledgments This paper was extracted from research project with code of 92062, and the authors wish to extend their sincere gratitude to all who have supported this work, especially Young Researchers and Elite Club of Flavarjan Islamic Azad University.

\section{References}

Abghari A, Chen SH (2014) Yarrowia lipolytica as an oleaginous cell factory platform for production of fatty acid-based biofuel and bioproducts. Front Energy Res 2:21. doi:10.3389/fenrg.2014. 00021 
Altamirano A, Vazquez F, De Figueroa LIC (2000) Isolation and identification of xylitol- producing yeasts from agricultural residues. Folia Microbiol (Praha) 45(3):255-258

Amaretti A, Raimondi S, Sala M, Roncaglia L, Lucia DM, Leonardi A, Rossi M (2010) Single cell oil of cold adapted oleaginous yeast Rhodotorula glacialis DBVPG 4785. Microbiol Cell Fact 23:59-73

Amaretti A, Raimondi S, Leonardi A, Rossi M (2012) Candida freyschussii: an oleaginous yeast producing lipids from glycerol. Chem Eng 27:139-144

Benjamas CH, Louhasakul Y (2013) Industrial wastes as a promising renewable source for production of microbial lipid and direct transesterification of the lipid into biodiesel. Bioresour Technol 142:329-337

Beopoulos A, Mrozova Z, Thevenieau F, Dall MTL, Hapala I, Papanikplaou S, Chardot T, Nicaud JM (2008) control of lipid accumulation in the yeast Yarrowia lipolytica. Appl Environ Microbiol 74(24):7779-7789

Bura R, Vajzovic A, Doty SL (2012) Novel endophytic yeast Rhodotorula mucilaginosa strain PTD3I: production of xylitol and ethanol. J Ind Microbiol Biotechnol 39(7):1003-1011

Cheng KK, Ling HZ, Zhang JA, Ping WZ, Huang W, Ge JP, Xu JM (2010) Strain isolation and study on process parameters for xylose to xylitol bioconversion. Food Biotechnol 24(1):1606-1611

Dai C, Tao J, Xie F, Dai YJ, Zhao M (2007) Biodiesel generation from oleaginous yeast Rhodotorula glutinis with xylose assimilating capacity. Afr J Biotechnol 6:2130-2134

Deak T, Chen J, Beuchat LR (2000) Molecular characterization of Yarrowialipolytica and Candida zeylanoides isolated from poultry. Appl Environ Mirobiol 66:4340-4344

Easterling ER, French WT, Hernandez R, Licha M (2009) The effect of glycerol as a sole and secondary substrate on the growth and fatty acid composition of Rodotorula glutinis. Bioresour Technol 100:356-361

Economou CN, Aggelis G, Pavlou S, Vayenas DV (2010) Modeling of single cell oil production under nitrogen-limited and substrate inhibition condition. Biotechnol Bioeng 108(5):1049-1055

Economou CHN, Aggelis G, Pavlou S, Vayenas DV (2011) Single cell oil production from rice hulls hydrolysate. Bioresour Technol 102(20):9737-9742

EL-Batal AI, Khalaf SA (2004) Xylitol production from corn cobs hemicellulosichydrolysate by Candida tropicalis immobilized cells in hydrogel copolymer carrier. IJAB 6(6):1066-1073

El-Fadaly H, El-Ahmady N, Marvan EM (2009) Single cell oil production by an oleaginous yeast strain in a low cost cultivation medium. Res J Microbiol 4(8):301-313

Enshaeieh M, Abdoli A, Nahvi I, Madani M (2012) Bioconversion of different carbon sources into microbial oil and biodiesel using oleaginous yeasts. J Biol Today's World 1(2):82-92

Enshaeieh M, Abdoli A, Nahvi I (2013a) Medium optimization for biotechnological production of single cell oil using Yarrowia lipolytica $\mathrm{M}_{7}$ and Candida sp. JCMR 5(1):17-23

Enshaeieh M, Abdoli A, Nahvi I, Madani M (2013b) Selection and optimization of single cell oil production from Rodotorula 110 using environmental waste as substrate. JCMR 4(2):1-10

Enshaeieh M, Nahvi I, Madani M (2014) Improving microbial oil production with standard and native oleaginous yeasts by using Taguchi design. Int J Environ Sci Technol 11(3):597-604

Fakas S, Papanikolaou S, Galiotou-Panayotou M, Komaitis M, Aggelis G (2008) Biochemistry and biotechnology of single cell oil. University of Patras, pp 38-60

Fei Q, Chang HN, Shang L, Choi JD, Kim N, Kang J (2010) The effect of volatile fatty acid as a sole carbon source on lipid accumulation by Cryptococcus albidus for biodiesel production. Bioresour Technol 102(3):2695-2701
Gong Z, Shen H, Wang Q, Yang X, Xie H, Zhao Z (2013) Efficient conversion of biomass into lipids by using the simultaneous saccharification and enhanced lipid production process. Biotechnol Biofiuels 6:36-54

Granstrom T (2002) Biotechnological Production of Xylitol with Candida Yeasts. Available in the electronic publications archive of Aalto University. ISBN 951-22-5992-3

Granstrom T, Izumori K, Leisola M (2007) A rare sugar xylitol PartI: the biochemistry and biosynthesis of xylitol. Appl Microbiol Biotechnol 74(2):277-281

Huang YT, Su CP (2014) High lipid content and productivity of microalgae cultivating under elevated carbon dioxide. Int $\mathrm{J}$ Environ Sci Technol 11(3):703-710

Huang C, Zong MH, Wu H, Liu QP (2009) Microbial oil production from rice straw hydrolysate by Trichosporon fermentans. Bioresour Technol 100:4535-4538

Huang CH, Chen XF, Xiong L, Chen X, Ma L (2012) Oil production by the yeast Trichosporon dermatis cultured in enzymatic hydrolysates of corncobs. Bioresour Technol 110:711-714

Huang CH, Chen XF, Xiong L, Chen XD, Ma L, Chen Y (2013) Single cell oil production from low-cost substrates: the possibility and potential of its industrialization. Biotechnol Adv 31(2):129-139

Ikeuchi T, Azuma M, kato J, Ooshima H (1999) Screening of microorganisms for xylitol production and fermentation behavior in high concentrations of xylose. Biomass Bioenerg 16:333-339

Karatay SE, Donmez G (2010) Improving the lipid accumulation properties of the yeast cells for biodiesel production using molasses. Bioresour Technol 101(20):7988-7990

Katre G, Joshi Ch, Khot M, Zinjarde S, Ravikumar A (2012) Evaluation of single cell oil (SCO) from a tropical marine yeast Yarrowia lipolytica NCIM 3589 as a potential feedstock for biodiesel. AMB Express 2:36-55

Khot M, Kamat S, Zinjarde S, Pant A, Chopade B, Ravikumar A (2012) Single cell oil of oleaginous fungi from the tropical mangrove wetlands as a potential feedstock for biodiesel. Microb Cell Fact 11(71):1-13

Kraisintu P, Yongmanitchai W, Limtong S (2010) Selection and optimization for lipid production of a newly isolated oleaginous yeast, Rdodosporidium toruloides DMKU3-TK16. Kasetsart J (Nat Sci) 44:436-445

Leesing R, Baojungharn R (2011) Microbial Oil production by isolated oleaginous yeast Torulaspora globosa YU5/2. WASET 76:799-803

Li YH, Liu B, Sun Y, Zhao ZB, Bai FW (2005) Screening of oleaginous yeasts for broad-spectrum carbohydrates assimilation capacity. Program Biotechnol 25:39-43

Li Q, Du W, Liu D (2008) Perspective ofmicrobial oils for biodiesel production. Appl Microbiol Biotechnol 80:749-756

Liu GY, Yuan S, Dai CC (2004) Factors affecting $\gamma$-linoleic acid content in fermented glutinous rice brewed by Rhizopus sp. Food Microbiol 21(3):299-304

Liu GQ, Lin QL, Jin XC, Wang XL, Zhao Y (2010) Screening and fermentation optimization of microbial lipid-producing molds from forest soils. Afr J microbiol Res 4(14):1462-1468

Mattanna P, Rosa PD, Poli J, Richards NSPS, Daboit TC, Scroferneker ML, Pastore APW, Corcao G, Bertoldi FC, Deschamps FC, Valente P (2014) Lipid profile and antimicrobial activity of microbial oils from 16 oleaginous yeasts isolated from artisanal cheese. Revista Brasileira de Biociências 12(2):121-126

Meng X, Yang J, Xu X, Zhang L, Nie Q, Xian M (2009) Biodiesel production from oleaginous microorganisms. Renew Energ 34:1-5

Muniraj IK, Xiao L, Hu Z, Zhan X, Shi J (2013) Microbial lipid production from potato processing wastewater using oleaginous filamentous fungi Aspergillus oryzae. Water Res 47(10):3477-3483 
Mussatto SI, Roberto IC (2008) Establishment of the optimum initial xylose concentration and nutritional supplementation of brewer's spent grain hydrolysate for xylitol production by Candida guilliermondii. Process Biochem 43:540-546

Pan LX, Yang DF, Shao L, Li W, Chen GG, Liang ZQ (2009) Isolation of oleaginous yeast from the soil and studies of their lipidproducing capacities. Food Technol Biotechnol 47(2):215-220

Papanikolaou S (2008) Current Topics on Bioprocesses in Food Industry, asiatech publishers Inc. 1, 3-Propanediol and citric acid production from glycerol containing waste discharged after biodiesel manufacturing process. pp 381-399

Papanikolaou S, Aggelis G (2003) Modeling lipid accumulation and degradation in Yarrowia lipolytica cultivated on industrial fats. Curr Microbiol 46(6):398-402

Papanikolaou S, Aggelis G (2011) Lipids of oleaginous yeasts. Part II: technology and potential applications. Eur J Lipid Sci Technol 113(8): 1052-1073

Papanikolaou S, Chevalot I, Komaitis M, Marc I, Aggelis G (2001) Single cell oil production by Yarrowia lipolytica growing on an industrial derivative of animal fat in batch cultures. Appl Microbiol Biotechnol 58:308-312

Pirozzi D, Ausiello A, yousuf A, Zuccaro G, Toscano G (2014) Exploitation of oleaginous yeasts for the production of microbial oils from agricultural biomass. Chem Eng 37:469-474

Rao RS, Bhadra B, Shivaji S (2007) Isolation and characterization of xylitol- producing yeasts from the gutofcolleopteran insects. Curr Microbiol 55(5):441-446

Rao RS, Jyothi CP, Rao LV (2008) Biothechnological production of xylitol by mutant Candida tropicalis OMV5: process optimization using statistical approach. IJBT 7:218-224

Raschke D, Knorr D (2009) Rapid monitoring of cell size, vitality and lipid droplet development in oleaginous yeast Waltomyces lipofer. J Microbiol Methods 79:178-183

Ratledge C (2002) Regulation of lipid accumulation in oleaginous micro-organisms. Biochem Soc Trans 30(6):1047-1050

Ratledge C (2005) Single cell oil for the 21st century, Cohen Z, Single Cell Oils, 978-1-893997-80-6. University of Hull, Hull, pp $1-20$

Sandhya M, Aravind J, Kanmani P (2013) Production of polyhydroxyalkanoates from Ralstonia eutropha using paddy straw as cheap substrate. Int J Environ Sci Technol 10(1):47-54

Santamauro F, Whiffin FM, Scott RJ, Chuck CHJ (2014) Low-cost lipid production by an oleaginous yeast cultured in non-sterile conditions using model waste resources. Biotechnol biofuels 7(34). doi:10.1186/1754-6834-7-34

Saxena RK, Anand P, Saran S, Isar J (2009) Microbial production of 1, 3-propanediol: recent developments and emerging opportunities. Biotechnol Adv 27:895-913

Schulze I, Hansen S, Großhans S, Rudszuck TH, Ochsenreither K, Syldatk CH, Neumann A (2014) Characterization of newly isolated oleaginous yeasts: Cryptococcus podzolicus, Trichosporon porosum and Pichia segobiensis. AMB Express 4(24). doi 10.1186/s13568-014-0024-0
Sriwongchai S, Pokethitiyook P, Kruatrachue M, Bajwa PK, Lee H (2013) Screening of selected oleaginous yeasts for lipid production from glycerol and some factors which affect lipid production by Yarrowia lipolytica strains. J Microbiol Biotechnol Food Sci 2(5):2344-2348

Susan HD, Maugeri F (2014) Prediction of quality properties for biodiesel production by oleaginous yeast cultivated in pure and raw glycerol. Chem Eng 37:465-468

Syed MA, Singh SK, Pandey A, Kanjilal S, Prasad RBN (2006) Effects of various process parameters on the production of $\alpha$ Linolenic acid in submerged fermentation. Food Technol Biotechnol 44:282-287

Tanimura A, Takashima M, Sugita T, Endoh R, Kikukawa M, Yamaguchi SH, Sakuradani E, Ogawa J, Ohkuma M, Shima J (2014) Cryptococcus terricola is a promising oleaginous yeast for biodiesel production from starch through consolidated bioprocessing. Sci Rep 4:4776

Tao J, Dai CC, Yang QY, Guan XY, Shao WL (2010) Production of biodiesel with acid hydrolysate of populus euramevicana $\mathrm{cv}$ leaves by Rhodotorula glutinis. Int J Green Energy 7:387-396

Toyoda T, Ohtaguchi K (2009) Xylitol production from lactose by biotransformation. J Biochem Tech 2(1):126-132

Tsigie YA, Wang CY, Truong CHT, Ju YH (2011) Lipid production from Yarrowia lipolytica Po1 g grown in sugarcane bagasse hydrolysate. Bioresour Technol 102(19):9216-9222

Vakhlu J, Kour A (2006) Yeast lipases: enzyme purification, biochemical properties and gene cloning. Electron J Biotechnol 9:69-85

Vijayakumar S, Kumutha K, Santhana Krishnan P, Gopal H (2010) Effect of carbon sources on lipid and biomass production by oleaginous yeast cultures. MAJ 97(1/3):62-64

Wu Q, Miao XL (2006) Biodiesel production from heterotrophic microalgal oil. Bioresour Technol 97:841-846

Yu XC, Zheng YB, Dorgan KM, Chen SL (2011) Oil production by oleaginous yeasts using the hydrolysate from pretreatment of wheat straw with dilute sulfuric acid. Bioresour Technol 102:6134-6140

Zagustina NA, Rodionova NA, Mestechkina NM, Shcherbukhin VD, Bezborodov AM (2001) Xylitol production by a culture of Candida guilliermondii2581. Appl Microbiol Biotechnol 37(5):489-492

Zhao X, Peng F, Du W, Liu C, Liu D (2012) Effects of some inhibitors on the growth and lipid accumulation of oleaginous yeast Rhodosporidium toruloides and preparation of biodiesel by enzymatic transesterification of the lipid. Bioprocess Biosyst Eng 35(6):993-1004

Zheng Y, Yu X, Zeng J, Chen Sh (2012) Feasibility of filamentous fungi for biofuel production using hydrolysate from dilute sulfuric acid pretreatment of wheat straw. Biotechnol Biofuels 5(50):1750-1754

Zhu LY, Zong MH, Wu H (2008) Efficient lipid production with Trichosporon fermentans and its use for biodiesel preparation. Bioresour Technol 99(16):7881-7885 